\title{
Cathodoluminescence Characterization of Maskelynite and Alkali Feldspar in Shergottite (Dhofar 019)
}

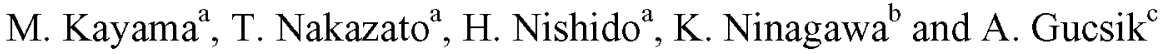 \\ ${ }^{a}$ Research Institute of Natural Sciences, Okayama University of Science, 1-1 Ridai-cho, Kita-ku, \\ Okayama, 700-0005, Japan. \\ ${ }^{\mathrm{b}}$ Department of Applied Physics, Okayama University of Science 1-1 Ridai-cho, Kita-ku, Okayama, \\ 700-0005, Japan \\ ${ }^{c}$ Max Planck Institute for Chemistry, Department of Geochemistry, Joh.-J. Becherweg 27, D-55128 \\ Mainz, Germany
}

\begin{abstract}
Dhofar 019 is classified as an olivine-bearing basaltic shergottite and consists of subhedral grains of pyroxene, olivine, feldspar mostly converted to maskelynite and minor alkali feldspar. The CL spectrum of its maskelynite exhibits an emission band at around $380 \mathrm{~nm}$. Similar UV-blue emission has been observed in the plagioclase experimentally shocked at 30 and $40 \mathrm{GPa}$, but not in terrestrial plagioclase. This UV-blue emission is a notable characteristic of maskelynite. CL spectrum of alkali feldspar in Dhofar 019 has an emission bands at around $420 \mathrm{~nm}$ with no red emission. Terrestrial alkali feldspar actually consists of blue and red emission at 420 and $710 \mathrm{~nm}$ assigned to $\mathrm{Al}-\mathrm{O}^{-}-\mathrm{Al}$ and $\mathrm{Fe}^{3+}$ centers, respectively. Maskelynite shows weak and broad Raman spectral peaks at around 500 and $580 \mathrm{~cm}^{-1}$. The Raman spectrum of alkali feldspar has a weak peak at $520 \mathrm{~cm}^{-1}$, whereas terrestrial counterpart shows the emission bands at $280,400,470,520$ and $1120 \mathrm{~cm}^{-1}$. Shock pressure on this meteorite transformed plagioclase and alkali feldspar into maskelynite and almost glass phase, respectively. It eliminates their luminescence centers, responsible for disappearance of yellow and/or red emission in CL of maskelynite and alkali feldspar. The absence of the red emission band in alkali feldspar can also be due to the lack of $\mathrm{Fe} 3+$ in the feldspar as it was reported for some lunar feldspars.
\end{abstract}

Keywords: Cathodoluminescence, Dhofar 019, Shergottite, Maskelynite, Alkali feldspar, Raman spectroscopy

PACS: 78.60. Hk, 87.64. Ea, 78.64.kp, 91.65. An, 96.25. Pq

\section{INTRODUCTION}

Martian meteorite of shergottite was severely shocked, and is considered one of the meteorites induced by highest shocked pressure, which causes phase transformation of plagioclase into maskelynite. It is regarded as a type material for maskelynite. Dhofar 019 is classified as an olivine-bearing basaltic shergottite. Shock pressure on this meteorite has been estimated at 30-35 GPa on the basis of the formation condition of maskelynite [1] and at 26-29 GPa evaluated from optical refraction factor of maskelynite [2]. Cathodoluminescence (CL) features such as intensity and peak position are related to composition, concentration of luminescence center and crystal

CP1163, Micro-Raman Spectroscopy and Luminescence Studies in the Earth and Planetary Sciences, edited by A. Gucsik

(C) 2009 American Institute of Physics 978-0-7354-0700-8/09/\$25.00 
fields, which can be altered by the pressure produced by shock metamorphism associated with impact events [3]. In this study, CL spectroscopy and microscopy of maskelynite and alkali feldspar in Dhofar 019 were carried out for CL characterization of these minerals. These results have been compared to $\mathrm{CL}$ data obtained from experimentally shocked plagioclase to interpret the effect of shock pressure on the CL properties of these minerals.

\section{SAMPLES AND METHODS}

Two polished thin sections of Dhofar 019 meteorite were employed for CL and Raman measurements. Dhofar 019 includes subhedral grains of pyroxene, olivine and feldspar mostly converted to maskelynite and minor alkali feldspar, merrillite, chromite, ilmenite and pyrrhotite, accompanied by terrestrial secondary phases. Maskelynite and alkali feldspar in this meteorite have a composition of $\mathrm{Or}_{0 \sim 4} \mathrm{Ab}_{43 \sim 58} \mathrm{An}_{38 \sim 57}$ and $\mathrm{Or}_{47 \sim 50} \mathrm{Ab}_{34 \sim 42} \mathrm{An}_{11 \sim 15}$, respectively.

Color CL images were captured using a cold-cathodoluminescence microscope (Luminoscope). A MiniCL system (Gatan) was employed for CL imaging at high magnification. CL spectra were measured in the range from 300 to $800 \mathrm{~nm}$ using a secondary electron microscope-cathodoluminescence (SEM-CL) system, which is comprised of a SEM (JEOL: JSM-5410) combined with a grating monochromator (OXFORD: Mono CL2). The Laser Raman spectroscopy (JASCO: NRS-2100) was carried out with an Ar laser of $514.5 \mathrm{~nm}$ wavelength with $20 \mathrm{~mW}$.

\section{RESULT}

Maskelynite in Dhofar 019 has a bright and dull emission with heterogeneous distribution of intensity in CL image pictured by MiniCL imaging system, whereas it shows no features such as zonal structures or lamellae in BSE image (Fig. 1a and b). The color CL image obtained with the Luminoscope also illustrates similar CL feature with bright blue emission and dull red one. Furthermore, the CL image reveals that prolonged electron irradiation causes a progressive decrease in their emission where electron irradiated area in maskelynite exhibits duller emission than does unirradiated one. BSE and CL images of mesostasis in this meteorite are shown in Figure 2. The mesostasis occurs as an anhedral crystal between olivine and pyroxene grains and consists of lath-shaped alkali feldspar superimposed on maskelynite in the core (Fig. 2a). The mesostasis in the rim has alkali feldspar with homogeneous composition of Orgo $_{90} \mathrm{Ab}_{10}$. The CL image of mesostasis obtained by MiniCL imaging system represents a bright emission of alkali feldspar and dull one of maskelynite, although color CL image captured with Luminoscope reveals that both minerals have a blue emission (Fig. 2). 
(a)

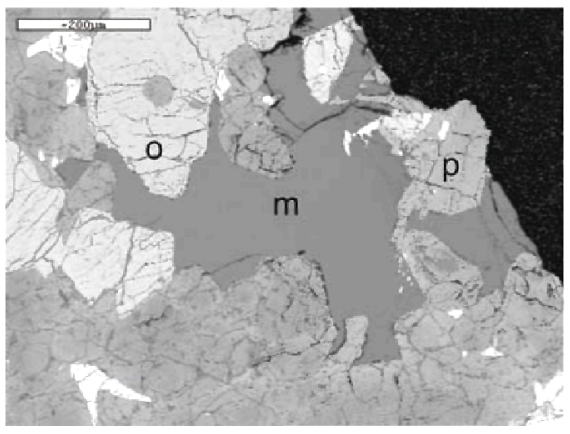

(b)

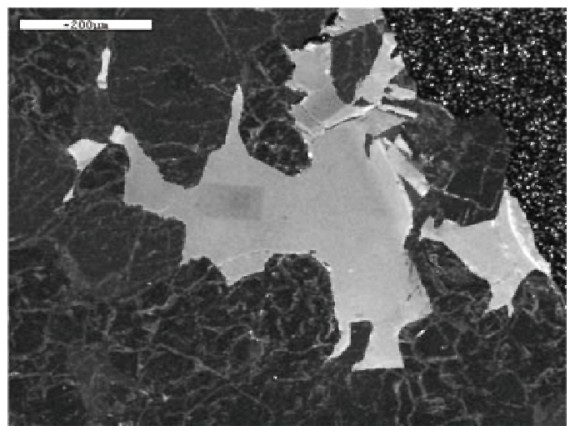

FIGURE 1. Maskelynite in Dhofar 019 (a) BSE image and (b) CL image; m: maskelynite, o: olivine and $\mathrm{p}$ : pyroxene

(a)

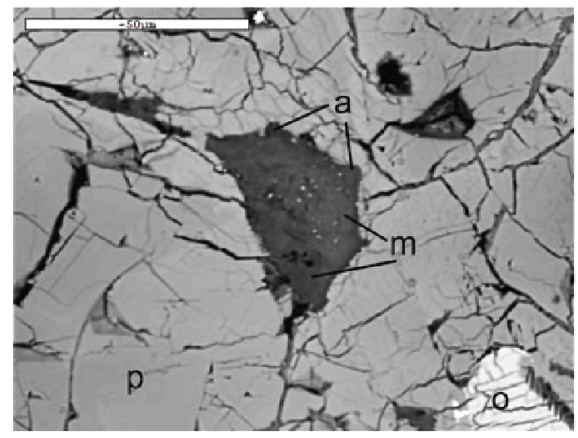

(b)

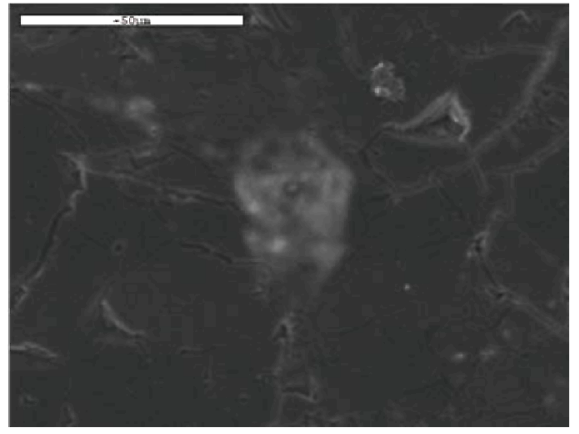

FIGURE 2. Alkali feldspar in Dhofar 019 (a) BSE image and (b) CL image; a: alkali feldspar, m: maskelynite, o: olivine and p: pyroxene

The CL spectrum of maskelynite shows an emission band at around $380 \mathrm{~nm}$ in the UV-blue region and has no other emission in the yellow and red spectral regions (Fig. 3a). Similar UV-blue has been also observed in plagioclase experimentally shocked at 30 and $40 \mathrm{GPa}$ [4]. Maskelynite indicates a rapid decay of its emission during electron irradiation, where CL intensity at $380 \mathrm{~nm}$ decreases with an increase in irradiation time at $15 \mathrm{kV}$ accelerating voltage and $2.0 \mathrm{nA}$ beam current. The Raman spectrum of maskelynite consists of weak and broad peaks at around 500 and $580 \mathrm{~cm}^{-1}$ and no pronounced peaks at around $170,280,480$ and $510 \mathrm{~cm}^{-1}$, which can be detected in terrestrial plagioclase (Fig. 3b).

The CL spectrum of alkali feldspar in Dhofar 019 is illustrated together with its Raman spectrum in Figure 4. It has an emission band at around $420 \mathrm{~nm}$ in blue region, whereas it shows no red emission, which is easily found in terrestrial alkali feldspar (Fig. 4a). Its Raman spectrum reveals a weak and broad peak at $520 \mathrm{~cm}^{-1}$, although terrestrial counterpart shows pronounced Raman peaks at 280, 400, 470, 520 and 1120 $\mathrm{cm}^{-1}$ (Fig. 4b). 
(a)

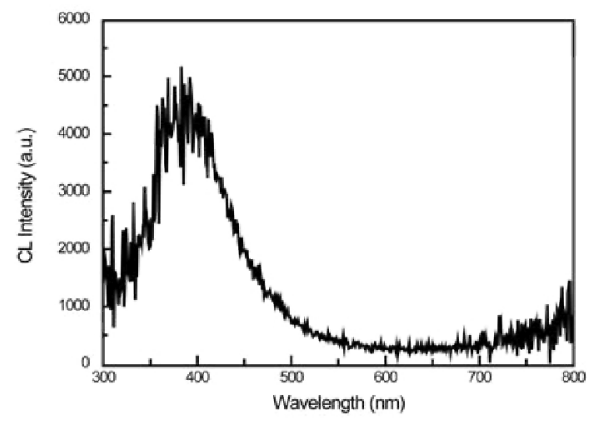

(b)

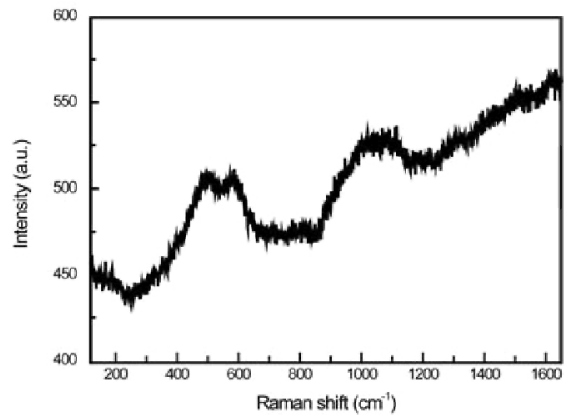

FIGURE 3. Maskelynite in Dhofar 019 (a) CL spectrum and (b) Raman spectrum

(a)

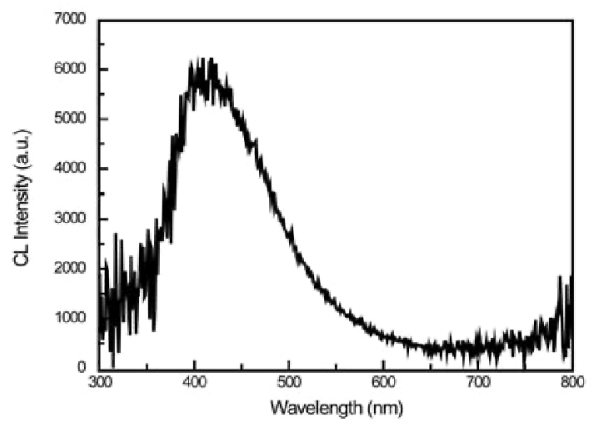

(b)

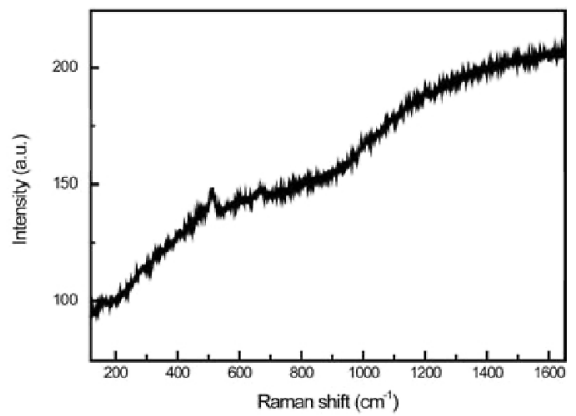

FIGURE 4. Alkali feldspar in Dhofar 019 (a) CL spectrum and (b) Raman spectrum

\section{DISCUSSION}

The Raman spectrum of maskelynite exhibits two weak and broad peaks at around 500 and $580 \mathrm{~cm}^{-1}$ which are also observed in plagioclase experimentally shocked at 40 GPa (Fig. 3b) [4]. Similar Raman spectra have been reported in previous Raman study on maskelynite in shergottites [5]. It indicates that plagioclase in Dhofar 019 completely transformed into maskelynite by shock metamorphism. CL spectroscopy and microscopy also reveal that maskelynite has a different $\mathrm{CL}$ features from terrestrial plagioclase. CL spectrum of maskelynite in Dhofar 019 shows an emission band with low intensity at around $380 \mathrm{~nm}$ in the UV-blue region without other emissions (Fig. 3a). Plagioclase in terrestrial rocks often have emission bands at around 420, 560 and $750 \mathrm{~nm}$ in blue, yellow and red regions which are assigned to Al$\mathrm{O}^{-}-\mathrm{Al}, \mathrm{Mn}^{2+}$ and $\mathrm{Fe}^{3+}$ center, respectively [6]. Furthermore, an emission band at around $380 \mathrm{~nm}$ has not been found in CL spectra of natural and synthetic plagioclase except for experimentally shocked ones at 30 and $40 \mathrm{GPa}$ [4]. According to Kayama et al [4], plagioclase experimentally shocked at $30 \mathrm{GPa}$ represents a dull emission in UV- 
blue and yellow spectral regions, and that at 40 GPa shows only an emission band with high intensity at around $380 \mathrm{~nm}$ [4]. This emission band at around $380 \mathrm{~nm}$ might be assigned to a shock-induced luminescence center, suggesting a CL signal characteristic of maskelynite. Maskelynite in Dhofar 019 exhibits no emission in the yellow region and has a quite weak CL intensity of UV-blue mission compared to experimentally plagioclase shocked at $40 \mathrm{GPa}$. Therefore, shock pressure induced on Dhofar 019 might be at 30 40 GPa. CL spectroscopy on this maskelynite also reveals that the $\mathrm{CL}$ emission shows a decay of the intensity during prolonged electron irradiation. CL intensities at $380 \mathrm{~nm}$ decrease with an increase in electron irradiation time. Such behavior is similar to short-lived luminescence reported in CL spectra of silica minerals [7]. The luminescence center related to emission at $380 \mathrm{~nm}$ might be eliminated by electron irradiation. The CL image of maskelynite has a heterogeneous distribution of its intensity. Similar CL behavior has been observed in plagioclase experimentally shocked at 20,30 and $40 \mathrm{GPa}$, but not in that of unshocked sample [4]. This heterogeneous distribution in the CL image of maskelynite in Dhofar 019 might depend on the difference of shock metamorphic effects between the areas with bright blue and dull red emission. The Raman spectrum of alkali feldspar in Dhofar 019 has only a weak peak at around $520 \mathrm{~cm}^{-1}$, whereas alkali feldspar from terrestrial rocks consists of pronounced Raman peaks at 280,400,470,520 and $1120 \mathrm{~cm}^{-1}$ assigned to $\mathrm{T}-\mathrm{O}-\mathrm{T}$ atomic vibration in framework structure (Fig. 4b). It implies that shock pressure on this meteorite causes partly destruction of the framework structure. The CL spectrum of this alkali feldspar shows an emission band at around $420 \mathrm{~nm}$, whereas terrestrial alkali feldspar actually consists of blue and red emission related to $\mathrm{Al}-\mathrm{O}^{-}-\mathrm{Al}$ and $\mathrm{Fe}^{3+}$ centers, respectively (Fig. 4a). It is important to note that the absence of the red $(\sim 700 \mathrm{~nm})$ emission in the meteoritic K-feldspar can probably also be explained by the lack of $\mathrm{Fe}^{3+}$ in these feldspars (similar to some lunar feldspars). It suggests that $\mathrm{Fe}^{2+}$ impurity might act as a non-luminescence center in almost glass alkali feldspar by shock metamorphism.

\section{ACKNOWLEDGMENTS}

We are deeply indebted to Satoshi Nakano (Shiga University, Japan) for valuable information and helpful discussion throughout this study. Authors are grateful for a review, which was given by Prof. Jens Götze at University of Freiberg (Germany).

\section{REFERENCES}

1. D. D. Badjukov, M. A. Nazarov, and L. A. Taylor, 32nd Lunar and Planetary Science Conference, Abstract. \#2195, (2001).

2. J. Fritz, N. Artemieva, and A. Greshake, Met. Planet. Sci. 40, 1393-1411 (2005).

3. R. F. Sippel and A. B. Spencer, Proc. Apollo 11 Lunar Sci. Conf. 3, 2413-2426 (1970).

4. M. Kayama, A. Gucsik, H. Nishido, K. Ninagawa and A. Tsuchiyama, Conference on Micro-Raman spectroscopy and Luminescence Studies, Abstract. \#3017, (2009).

5. J. Fritz, A. Greshake, and D. Stöffler, Antarct. Meteorite. Res. 18, 96-116 (2005). 
6. J. Götze, M. R. Krbetschek, D. Habermann, and D. Wold, "High-resolution cathodoluminescence of feldspar minerals" in Cathodoluminescence in Geosciences, edited by M. Pagel, V. Barbin, Ph. Blanc, and D. Ohnenstetter, Berlin: Springer Verlag, 2000, pp. 245-270.

7. M. Kayama, H. Nishido, and K. Ninagawa, Amer. Mineral (in press). (2009) 